\title{
MEASURING RAPID TRANSIT ACCESSIBILITY AND EQUITY IN MIGRANT COMMUNITIES ACROSS 17 EUROPEAN CITIES
}

\author{
ALEXANDROS BARTZOKAS-TSIOMPRAS \& YORGOS N. PHOTIS \\ Laboratory of Geography \& Spatial Analysis, National Technical University of Athens, Greece
}

\begin{abstract}
Migrants in cities are highly dependent on frequent and fast public transport services. Easy access to rapid transit stations, such as subways or suburban rails, plays a crucial role in shaping migrants' daily lives and critically influences integration processes at the local level. Nevertheless, in Europe, little is known about migrants' access to rapid transport facilities. This article is the first one that provides comparable local indicators of rapid transit accessibility and equity in the supply of transit services for various migrant and non-migrant groups across 17 European cities. Our analysis was based primarily on an innovative European spatial dataset about migrants' concentration in cities as well as on several openly available general transit feed specification datasets. Methodologically, we used a classic gravity-based accessibility model, where the average frequency of daily departures was assumed as the attractiveness factor of the instrument. On the other hand, we performed Gini coefficient analysis and created Lorenz curve graphs to assess transit equity. The results allowed us to make inter- or intracity comparisons and to demonstrate some of the most transit disadvantaged migrant communities in Europe. Our findings suggest that Africans experience on average the worst access, while Americans, in the vast majority of cities, are located in high-access districts. Also, transit equity assessment demonstrated a high level of inequality across all population groups and cities, except Barcelona. A striking result was that $88 \%$ of African communities in Turin shared only $10 \%$ of rapid transit supply. However, it was confirmed that regardless of people's nationality, in many cities around Europe, it is difficult for many dwellers to live in close proximity to subways. Therefore, better land-use and mobility policies are required to guide cities towards more inclusive and sustainable urban development.
\end{abstract}

Keywords: European cities, gravity index, migrants, rapid transit, transit accessibility, transit equity.

\section{INTRODUCTION}

This study delves into the concept of rapid transit accessibility and equity from the immigration point of view. This research field remains largely unexplored [1] in Europe, and it is relevant to two key policy domains - sustainable urban mobility and integration of migrants in cities.

Today, migration is a significant issue in Europe that dominates policy and political agendas. Yet, little is known about migrants' integration processes at the local level [2], and new insights and indicators are required to promote inclusive and sustainable urban development. One of the most significant aspects of local integration strategies is transit accessibility, because migrants are highly dependent on public transport [3] and have a powerful impact on urban mobility policy [4]. In this case, easy access to rapid transit systems, such as subways and suburban rails, can act as a catalyst for a better society because it is the most effective and sustainable way to quickly transport large numbers of people to various regional or local destinations, such as jobs, healthcare, education, food markets and recreation [5]. There is ample literature on how access to transit influences transit use [6] and how it contributes to climate change mitigation, social cohesion, employment and improved public health [7]. However, in many cities, the distribution of transportation services is highly unequal [8], and it is unclear if transport and city planning fulfils the needs of the most vulnerable groups, 
such as migrants, efficiently and equally. For instance, a Canadian study found that socially disadvantaged residents have better transit accessibility than the more affluent groups [9], while findings from Australia highlighted a clear mismatch between transit supply and social needs [10].

Therefore, inequality in transit services and inaccessibility to the rapid transit systems among different ethnic population groups in European urban areas are key concerns of this study. Findings from this research can be of interest to urban and transportation planning practitioners, European policy analysts and decision-makers to help them put into practice strategies that support inclusive, liveable and sustainable societies. Hence, two fundamental research questions aim to find answers:

- Which cities offer migrants the best/worst accessibility to rapid transit?

- Which migrant groups and cities show the highest/lowest level of equality in rapid transit supply?

Two classical indicators have been created to answer the questions above, a gravity-based accessibility index and the Gini coefficient, with the following operational characteristics in principle: (1) comparable geographies between cities, (2) easy to implement, interpret and communicate and (3) sensitive to changes in population and transport service distribution. The next section presents a literature review. Section 3 describes the methodological framework and the data sources. Section 4 elaborates some necessary information about the selected European cities. Section 5 describes the results and finally Section 6 summarises the findings of the study.

\section{LITERATURE REVIEW}

Accessibility is a spatial concept. It refers to the ease of traveling to destinations and comprises an essential condition for ensuring the well-being and efficient functioning of cities. Back in the 1920s, accessibility was used in location theory and regional economic planning [11] and for the first time was defined by Hansen [12] as a potential for opportunities for interaction. Extensive details about accessibility measures can be found in the review of Geurs \& van Wee [13]. However, three broad types of accessibility instruments are commonly mentioned in the literature: (1) count-based opportunities measures, (2) gravity-based measures and (3) utility-based measures. In this section, we will focus on transit accessibility indicators, transit equity measures and the relation of migrants with public transport.

\subsection{Transit accessibility measures}

Measures of access to transit have repeatedly been studied by several researchers [7]. The most common approaches include the calculation of proximity of demand to stops in time or distance, the duration of transit journey and the accessibility of land uses via transit [14]. A simple example of these concepts is the people near rapid transit (PNT) index, which measures the population who lives within $1 \mathrm{~km}$ of high-quality rapid transit in 25 large cities around the globe [5]. Nevertheless, this concept of transit accessibility is quite incomplete and often criticised for ignoring the service frequencies on the calculations. Lately, the increasing publication of openly available transit micro-data, such as the general transit feed specification (GTFS) data format, attracted the attention of transportation geographers, and many transit accessibility models have started to include the number of services [15], [16]. For 
instance, Poelman \& Dijkstra [15] suggested a methodology of comparable public transport accessibility indicators across European urban areas by using common city boundaries and transit supply. Their approach was relatively simple and combined GTFS data with population distributions in order to create five levels of access based on three criteria: (1) proximity of population to bus/tram stops, (2) proximity of population to subway/rail stations and (3) the average daily service frequencies per stop.

On the other hand, gravity-based models simulate the reality better than the simple countbased measures. In this type of accessibility, a travel impedance measure is involved, and thus the attractiveness of destinations decreases with the distance from the origin. Hansen [12] introduced this gravity method to measure job access, and so far, it has been used in numerous analyses with various formulas [17]. An example of gravity-based transit accessibility analysis includes the study of Cambel et al., which estimates the number of health facilities in Nairobi, Kenya, that can be reached in 60 minutes by transit. Additionally, Piovani et al. [18] used a gravitational indicator to assess the impact of a new bus rapid transit (BRT) system in Brazil on job accessibility. However, some problems and limitations exist. First, it is not easy to interpret the results [19]. For example, a survey about the views of experts about a gravity-based accessibility instrument in Rome indicated that $50 \%$ of them did not understand it easily, while $63 \%$ of them found the results of the model very useful and $88 \%$ agreed that it is an appropriate tool for urban mobility policy [20]. Second, the input data in many gravity models are often given in zones, and consequently, the distances between the zones are based on the distances between their centroids [17]. Third, gravity models do not incorporate the user's perspectives in measuring the attractiveness of public transport stops, and often the results overestimate transit access [21].

On the other hand, utility-based methods overcome some of the gravity and count-based models' limitations, as they take into consideration the individual's perspective of ease in accessing transit. Hence, the utility-based models capture the net benefits that an individual gains in using the opportunities accessible within a given travel impedance [12]. Nassir et al. [16] developed a utility-based instrument to conceptualise public transport network accessibility in Brisbane, Australia. Their accessibility model was a nested logit 'logsum' composition, and the results were based on the subjective perceptions of the impedance of transit users when traveling in the network. Utility-based accessibility models, when compared with the gravitational and count-based methods, are more precise and sophisticated; however, they require a large amount of data [21].

\subsection{Transit equity measures}

There is a rich body of literature about transit equity measures [8], [22]. Equity in transportation planning pertains to the fairness of the distribution of the transportation supply among the population [22]. There are two main types of equity [9]: (1) the horizontal equity, where all individuals or groups are treated the same and (2) the vertical equity, where vulnerable groups receive greater benefits than others do. Until now, several statistical measures have been proposed in equity concepts. The most popular technique is the statistical dispersion measure of the Gini coefficient [23]; however, other methods include the Theil index, the coefficient of variation and the range. In this study, we will focus on the Gini indicator; thus, for a more analytical review of equity measures see Ramjerdi [24].

The work of Delbosc and Currie [22] and Ricciardi et al. [25] provides good examples of using Gini coefficient $(G$. ) analysis in investigating horizontal and vertical transit equity. 
They developed and mapped a transit supply index, and in turn, they assessed the social exclusion effects of public transport services in the Australian cities of Melbourne and Perth. The Gini coefficient values indicated that Perth $(G .=.52)$ experienced a less inequitable supply of public transport than Melbourne $(G .=.68)$, which means that $70 \%$ of the population received $19 \%$ and 33\% of Melbourne's and Perth's transit supply, respectively. Another study in Copenhagen, Denmark, applied a Gini coefficient analysis based on the scores of a gravity-based accessibility indicator [26] and concluded that the distribution of the transit supply presented substantial levels of equality $(G .=.31)$. Similarly, other authors found a Gini coefficient value of .32 in Beijing, China, for the bus network supply [27]. Welch and Mishra [28] developed a transit connectivity index and a Gini indicator for equity to measure how changes in transit service affect equality in several locations in Washington, D.C., and the Baltimore region. They found considerable variations of the Gini coefficient values between regions, ranging from .48 in Prince George's County to .83 in Maryland, which is close to perfect inequality. Nevertheless, we should highlight that although the Gini index is scale independent, it relies on the choice of the accessibility measure [23]. Therefore, comparisons of different accessibility approaches in transit equity concepts should be treated with caution.

\subsection{Migrants and transit}

Travel behaviour may be influenced by ethnic background [1], [29]. Studies from the United States indicated that cities with a higher proportion of migrants also have higher transit ridership [3]. These results imply that migration has powerful consequences for urban mobility policy [4]. However, in Europe, there is little research on migrants and public transport. Most of the existing data and studies present evidence mainly at the national level. For example, a UK project [30] found that 54\% of the non-European Economic Area (EEA) population use public or active transport, while $74 \%$ of the UK nationals use cars. A study from Denmark and the Netherlands found that migrants cycle less than non-migrants do [29]. At the local level, an empirical study in Offenbach am Main, Germany [1], found that migrants, especially women, use public transport or ride in a car as a passenger regularly, while the vast majority of migrants lack vehicle ownership. Concerning migrants' accessibility to transit, the research in Europe is still insignificant. We found only one relevant study, which indicated the negligible access of migrants to the subway stations of Stockholm, Sweden [57].

\section{METHODOLOGY}

\subsection{Data sources}

\subsubsection{City boundaries}

One of the main objectives of the current study is to provide a meaningful benchmark of migrants' accessibility to rapid transit in European cities. Hence, our cross-city analysis should be based on common geographies for the comparisons to make sense. The new OECD-EU harmonised geographic definition of a city [15] created the urban centre boundaries, which according to Eurostat's glossary are 'clusters of contiguous grid cells of $1 \mathrm{~km}^{2}$ (excluding diagonals) with a population density of at least 1.500 inhabitants per $\mathrm{km}^{2}$ and collectively a minimum population of 50.000 inhabitants after gap-filling'. Therefore, our calculations are based on the high-density cluster (2011) areas [31]. 


\subsubsection{D4I population spatial data of migrants}

At the end of 2017, the Joint Research Centre (JRC) of the European Commission launched an initiative about a Data Challenge on Integration of Migrants in Cities (D4I) [32]. The objective of this project was to disseminate a large dataset showing the concentration of migrants in EU cities and towns of eight EU countries (i.e. Germany, France, Italy, Spain, Netherlands, Portugal, Ireland and the UK) at a high spatial resolution $(100 \mathrm{~m}$ by $100 \mathrm{~m})$ grid. The D4I data refer to the 2011 census dataset provided by the national statistical agencies, and the population is grouped at three levels of aggregation: (1) L1: by specific country, (2) L3: by continent and (3) L4: by EU versus non-EU country. In this study, we used only the L3 level, which categorises the population into six types: (1) Europe, (2) America, (3) Asia, (4) Africa, (5) Oceania, (6) native-born and (7) other. However, we did not report any results for the 'Oceania' and 'Other' groups due to their small population size in the selected cities.

\subsubsection{Transit and timetable data}

The proposed accessibility indicator of this study requires pre-aggregated data about the location of stops and the offered transit services. For this purpose, we created a geographic information system (GIS) database with several GTFS datasets from various cities. This GTFS data format includes both spatial information and transit schedules. The GTFS data for this study were retrieved from the following websites: (1) https://transitfeeds.com and (2) https://navitia.opendatasoft.com. Furthermore, the analysis of this kind of transit data was conducted on the Esri's ArcGIS v.10.3 software with the support of Esri's GTFS analysis toolboxes (https://esri.github.io/public-transit-tools/index.html). Notably, we used the BetterBusBuffers tool to calculate the average number of departures in each subway or rail stop for a typical weekday between 06:00 and 20:00. Nonetheless, for homogeneity and comparability reasons for the different GTFS sources, stops that were less than $50 \mathrm{~m}$ apart were clustered in a single point, while for each of these clusters the sum of the hourly average number of departures was calculated [15].

\subsection{Gravity-based rapid transit accessibility index}

To measure rapid transit accessibility, we used a classic gravity-based model. Accordingly, stops that were closer to the points of origin (D4I population grid) received greater weight than those that were more distant. Additionally, each stop received as an attractiveness factor the average number of departures per hour. Technically, the index was computed on ArcGIS v.10.3 software with the support of Harvard University's City Form Lab Urban Network Analysis (UNA) tool [33]. The UNA tool applied eqn. (1), while the calculations were based on pre-processed street network data derived from the Openstreetmap.org (i.e., non-walkable road segments, such as motorways, have been excluded from the analysis):

$$
\text { Gravity }[i]^{r}=\sum_{j \in G-\{i\}, d[i, j] \leq r} \frac{W_{j}}{e^{\beta \cdot d[i, j]}} .
$$

In formula (1), Gravity [i] $]^{r}$ is the gravity index at point $i$ within graph $G$ at search radius $r, W_{j}$ is the weight of destination $j, d[i, j]$ is the geodesic distance between points $i$ and $j$ and $\beta$ is the exponent for adjusting the effect of distance decay. As a search radius, we used the threshold of $833 \mathrm{~m}$ [15], while the $\beta$ value for impedance was set at 0.00217 [33]. 


\subsection{Gini coefficient and Lorenz curves}

For each city, the Gini indicator measures the rapid transit supply inequality. This indicator of transit equity is a global statistical measure of dispersion, and it does not consider the spatial distribution of supply and demand [24], [23]. In the framework of this study, as supply, it is assumed the value of the gravity-based accessibility index, and as demand, it is defined as the number of migrant or non-migrant people. The Gini indicator was calculated on R Studio software with the utilisation of the DescTools R package and the gini function. The mathematical calculation of the Gini coefficient uses eqn. (2).

$$
G=1-\sum_{k=1}^{n}\left(X_{k}-X_{k-1}\right)\left(Y_{k}-Y_{k-1}\right),
$$

where $X_{\mathrm{k}}$ is the cumulated proportion of the population variable, for $k=0, \ldots, n$, with $X_{\mathrm{o}}=0$, $X_{\mathrm{n}}=1$ and $Y_{\mathrm{k}}$ is the cumulated proportion of the rapid transit accessibility index, for $k=0, \ldots, n$, with $Y_{\mathrm{o}}=0, Y_{\mathrm{n}}=1$.

What is more, to get a better understanding of the Gini values we also applied Lorenz curves, which are a visual illustration of equality [22]. Lorenz curves have been widely used in economics to display the cumulative distribution of wealth across the population. Accordingly, in a Lorenz curve graph, the diagonal line - i.e., when $x=y$ - symbolises perfect equity, while the bigger the total area under that line it is, the higher the level of inequality.

\section{CASE STUDY: 17 EUROPEAN CITIES}

This article measures rapid transit accessibility and equity in 17 European cities of six EU countries - Germany, France, Italy, Spain, Netherlands and Portugal. The selection of cities was based on the following criteria: (1) availability of subway and suburban rail GTFS data, (2) operation of at least one subway line and (3) the total share of the foreign-born population in the city is higher than $5 \%$.

Table 1 illustrates the synthesis of the population in each city and the ratio of rapid transit stops per 100,000 people. The range of the foreign-born population varies from $27 \%$ in Stuttgart to $8 \%$ in Lille. African communities are the largest in all French cities and Lisbon. American communities are the largest in Spanish cities. Asian communities are the largest in the Dutch cities and Milan, while European migrant communities are the biggest in the German cities as well as in Rome and Turin. Finally, Lille, Stuttgart, Berlin, Hamburg and Toulouse demonstrated some of the highest ratios of stops per 100,000 people.

\section{RESULTS}

\subsection{Accessibility to rapid transit}

The results are dependent on four factors: (1) the number of rapid transit facilities, (2) the frequencies of departures, (3) the density of the street network and (4) the distribution of the population. Figure 1 presents the average values of the gravity-based accessibility indicator for each migrant and non-migrant group and city.

Overall, the cities of Barcelona, Paris and Toulouse demonstrated the best performance on the gravity indicator, while Lisbon, Amsterdam, Rotterdam and Rome had the worst performance. Regarding the accessibility results per migrant group, we found that Africans had the lowest average accessibility (see Fig. 1: orange dashed line), while Americans demonstrated the highest level of access to rapid transit (see Fig. 1: purple dashed line). However, due to 
Table 1: (i) Population shares of migrant and non-migrant groups and (ii) the ratio of rapid transit stops (clusterised) per 100,000 people across 17 European cities.

\begin{tabular}{|c|c|c|c|c|c|c|c|c|c|c|c|}
\hline \multirow[t]{3}{*}{ City } & \multicolumn{8}{|c|}{ Migrants } & \multicolumn{2}{|c|}{ Non-migrants } & \multirow{3}{*}{$\begin{array}{l}\text { Total } \\
\text { population }\end{array}$} \\
\hline & \multicolumn{2}{|c|}{ Africans } & \multicolumn{2}{|c|}{ Americans } & \multicolumn{2}{|l|}{ Asians } & \multicolumn{2}{|c|}{ Europeans } & \multicolumn{2}{|c|}{ Native-born } & \\
\hline & (i) & (ii) & (i) & (ii) & (i) & (ii) & (i) & (ii) & (i) & (ii) & \\
\hline tutt & $\%$ & 3973 & $\%$ & 5605 & $7,0 \%$ & 524 & $16,5 \%$ & 221 & $72,7 \%$ & 50,3 & .310 \\
\hline Amsterdam & $5,7 \%$ & 121 & $6,8 \%$ & 102 & $7,8 \%$ & 89 & $5,6 \%$ & 125 & $73,9 \%$ & 9,4 & 1.050 .933 \\
\hline Rotterdam & $4,8 \%$ & 128 & $6,9 \%$ & 89 & $7,4 \%$ & 83 & $4,4 \%$ & 141 & $76,4 \%$ & ,1 & 350 \\
\hline Hamburg & $1,0 \%$ & 983 & $0,7 \%$ & 1373 & $6,5 \%$ & 145 & $9,2 \%$ & 103 & $80,1 \%$ & 11,9 & 1.523 .122 \\
\hline erlin & $0,6 \%$ & 1428 & $0,7 \%$ & 1284 & $6,1 \%$ & 148 & $9,8 \%$ & 93 & 81 , & 11,2 & 162 \\
\hline Barcelona & $1,6 \%$ & 409 & $9,6 \%$ & 68 & $2,1 \%$ & 320 & $3,5 \%$ & 190 & $83,2 \%$ & 7,9 & .342 \\
\hline isbon & $9,1 \%$ & 60 & $3,1 \%$ & 175 & $0,9 \%$ & 611 & $2,4 \%$ & 223 & $84,5 \%$ & 6,4 & 1.7 \\
\hline Paris & $6,8 \%$ & 55 & $0,8 \%$ & 472 & $2,6 \%$ & 144 & $4,4 \%$ & 86 & $85,5 \%$ & 4,4 & 8.334 .399 \\
\hline Madri & $1,1 \%$ & 655 & $8,9 \%$ & 78 & $0,8 \%$ & 892 & $3,6 \%$ & 193 & $85,7 \%$ & 8,1 & 3.908 .972 \\
\hline Milan & $2,1 \%$ & 313 & $2,5 \%$ & 262 & $3,4 \%$ & 190 & $3,1 \%$ & 206 & $89,0 \%$ & 7,2 & 2.839 .130 \\
\hline Turin & $2,5 \%$ & 118 & $1,2 \%$ & 242 & $1,0 \%$ & 302 & $6,1 \%$ & 49 & $89,2 \%$ & 3,4 & 1.134 .718 \\
\hline Valencia & $0,8 \%$ & 804 & $5,6 \%$ & 113 & $0,8 \%$ & 821 & $3,1 \%$ & 209 & $89,7 \%$ & 7,1 & 1.285 .023 \\
\hline Lyon & $5,4 \%$ & 124 & $0,4 \%$ & 1888 & $1,3 \%$ & 504 & $2,8 \%$ & 242 & $90,1 \%$ & 7,5 & 923.321 \\
\hline Rome & $1,0 \%$ & 622 & $1,1 \%$ & 576 & $3,1 \%$ & 199 & $3,5 \%$ & 172 & $91,4 \%$ & 6,7 & 2.316 .479 \\
\hline Toulouse & $4,4 \%$ & 223 & $0,5 \%$ & 2062 & $1,0 \% 1$ & 1033 & $2,7 \%$ & 373 & $91,5 \%$ & 10,9 & 503.594 \\
\hline Marseille & $5,5 \%$ & 83 & $0,1 \%$ & 3271 & $1,0 \%$ & 455 & $1,3 \%$ & 338 & $92,0 \%$ & 4,9 & 836.035 \\
\hline Lille & $4,9 \%$ & 230 & $0,1 \%$ & 11203 & $0,8 \% 1$ & 1456 & $1,9 \%$ & 602 & $92,3 \%$ & 12,3 & 766.795 \\
\hline
\end{tabular}

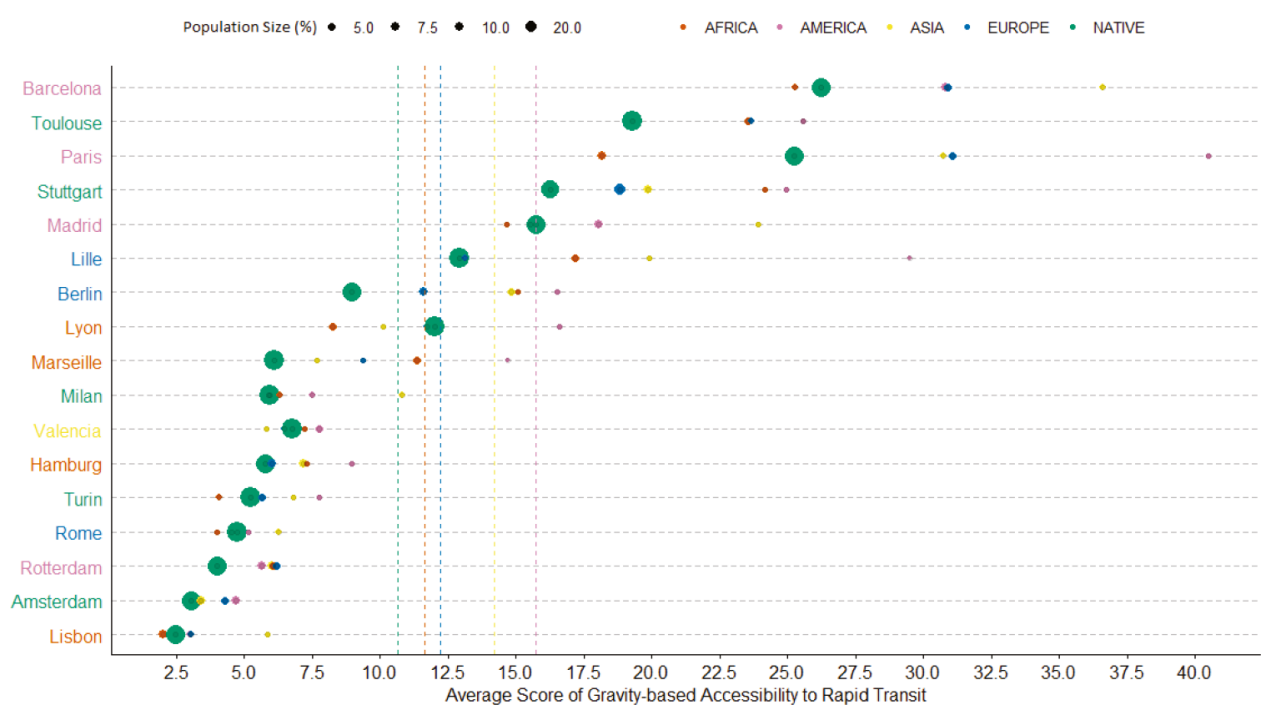

Figure 1: Average scores of the gravity-based accessibility index. Vertical dashed lines represent the grand mean of the gravity index of all cities per population group. 
significant differences in the length of transit systems and the service frequencies, the variation of the accessibility scores across and within cities was substantial. For example, the highest accessibility value was indicated for Americans in Paris (40.49), whereas the lowest score pointed out was for Africans in Lisbon (2.02). In addition, the differences of the accessibility results between the population groups were extremely high in some cities, namely in Paris, Lille and Barcelona, but low in Valencia, Rome, Amsterdam and Rotterdam.

In particular, Barcelona and Paris were found to be the cities with the highest accessibility values in almost all population groups. The exception in this pattern was the African migrants, which showed the highest accessibility scores in Barcelona (25.28) and Stuttgart (24.18). On the other extreme, Lisbon and Amsterdam presented the lowest mean values for all migrant and non-migrant groups. Only Asians, however, presented a slightly different pattern, where the lowest accessibility was highlighted in Amsterdam (3.44) and Valencia (5.83).

Comparing the average scores of migrant and non-migrant groups in each city individually, we found that the native-born population in comparison to the other groups had the worst mean accessibility value in 7 of 17 cities. Notably, we noticed that in all German and Dutch cities, the native-born population lived in lower accessibility areas than any other foreign-born group. Similarly, African communities scored worse than the other groups in eight urban areas, namely in Paris, Lyon, Marseille (Fig. 2), Lisbon, Rome, Turin (Fig. 2), Barcelona and Madrid. European migrants were the most transit disadvantaged group only in Milan and Asians only in Valencia. Nevertheless, American migrants were not found to be the worst performing cohort in any city.

On the other hand, American-born migrants presented the best average accessibility in comparison to the other groups in all cities except the following six - Barcelona, Madrid, Milan, Rome, Rotterdam and Lisbon. Moreover, the accessibility performance of Asian communities stood out in the following five cities - Barcelona, Madrid, Rome, Milan and Lisbon (Fig. 2) - while Europeans' accessibility results outperformed the other groups only in Rotterdam. The results for the native-born population and Africans showed they were not found to excel in any city.

Figure 3 represents the percentages of the population with no access to rapid transit stations; in other words, it illustrates the zero scores of the gravity index. The variation of the results was substantial. For instance, $78.9 \%$ of Africans in Turin lived outside the service areas of rapid transit (Fig. 2), whereas in Barcelona only 5.25\% of Asians had no easy access to subways or rail stations (Fig. 2). However, in seven cities, the results were reportedly problematic, and the percentages were higher than $50 \%$ for almost all population groups, namely in Turin, Lisbon, Amsterdam, Rotterdam, Lyon, Milan and Rome. On the contrary, three cities stood out - Barcelona, Madrid and Stuttgart - where the share of the population with zero accessibility was roughly lower than $25 \%$ for all population groups.

\subsection{Equity in rapid transit supply}

Figures 4 and 5 illustrate the results of the Gini coefficient $(G$.) analysis and the Lorenz curves. By and large, all cohorts of the foreign-born and the native-born population showed Gini values higher than 0.5 and lower than 0.89 , indicating a landscape of substantial transit inequality within the minority and majority groups in Europe. Nevertheless, we observed two important results. First, Barcelona presented the highest level of equality in rapid supply, where the Gini coefficients were lower than 0.44 in all cohorts, and second, Americans demonstrated in Marseille the lowest value in Gini coefficient analysis, with 0.35. This means 

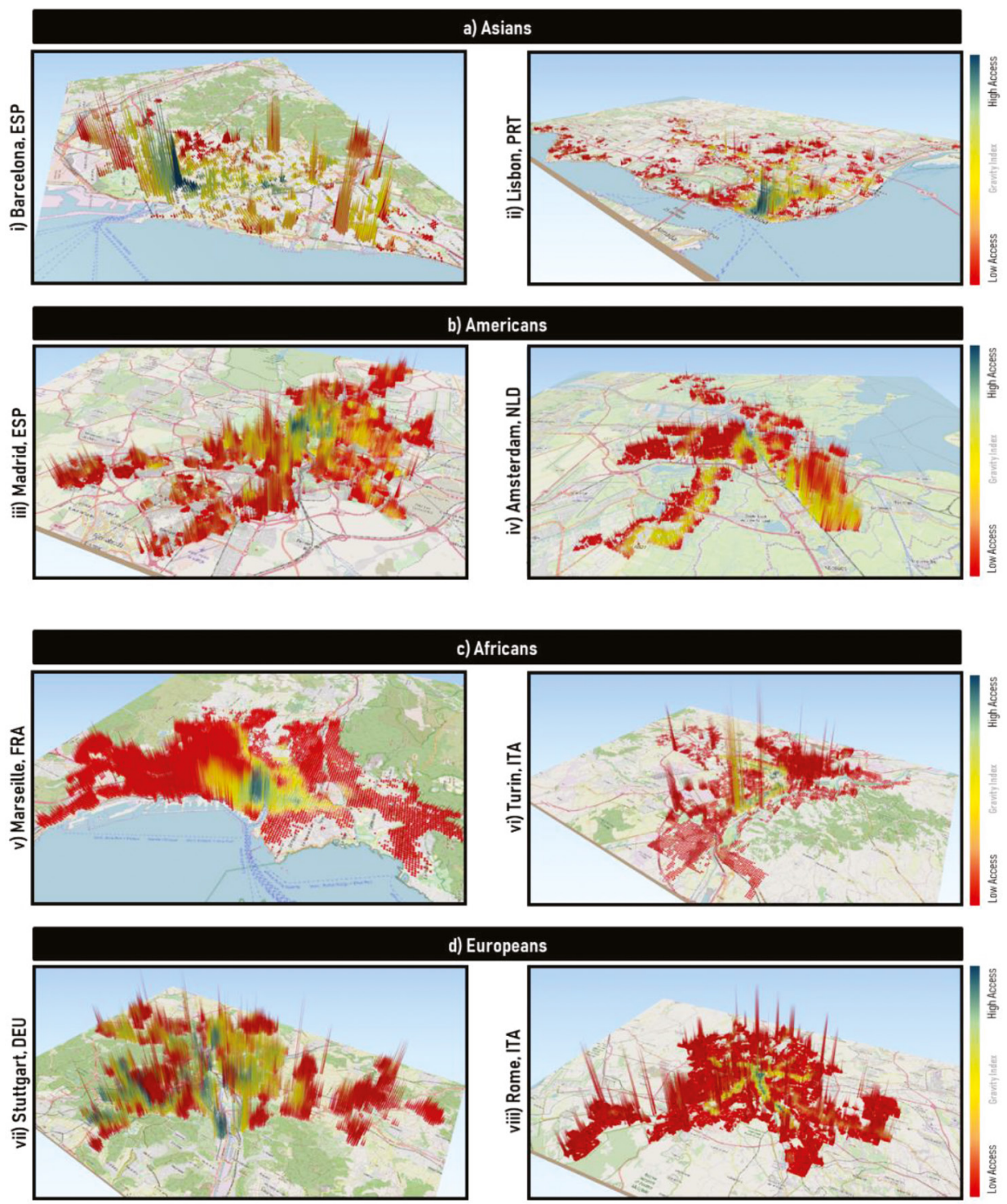

Figure 2: In the above 3D maps, the colours represent the gravity-based accessibility scores, while the height of the cones depicts the migrants' concentration.

that $90 \%$ of Americans in Marseille shared about $70 \%$ of the rapid transit supply, which translates into a case of significant transit equity (see Fig. 5). On the other extreme, Turin, Rome and Amsterdam demonstrated the greatest level of inequality in all groups and cities, since the Gini coefficient results had values higher than 0.7 . To give an illustration of this level of inequality, $88 \%$ of the African population in Turin and Rome received only $10 \%$ and $21.6 \%$ of the rapid transit supply, respectively, while $70 \%$ of Asians $(G .=0.78)$ in the Dutch capital shared only $5 \%$ of the supply (see Fig. 5). Similar levels of transit inequality were 


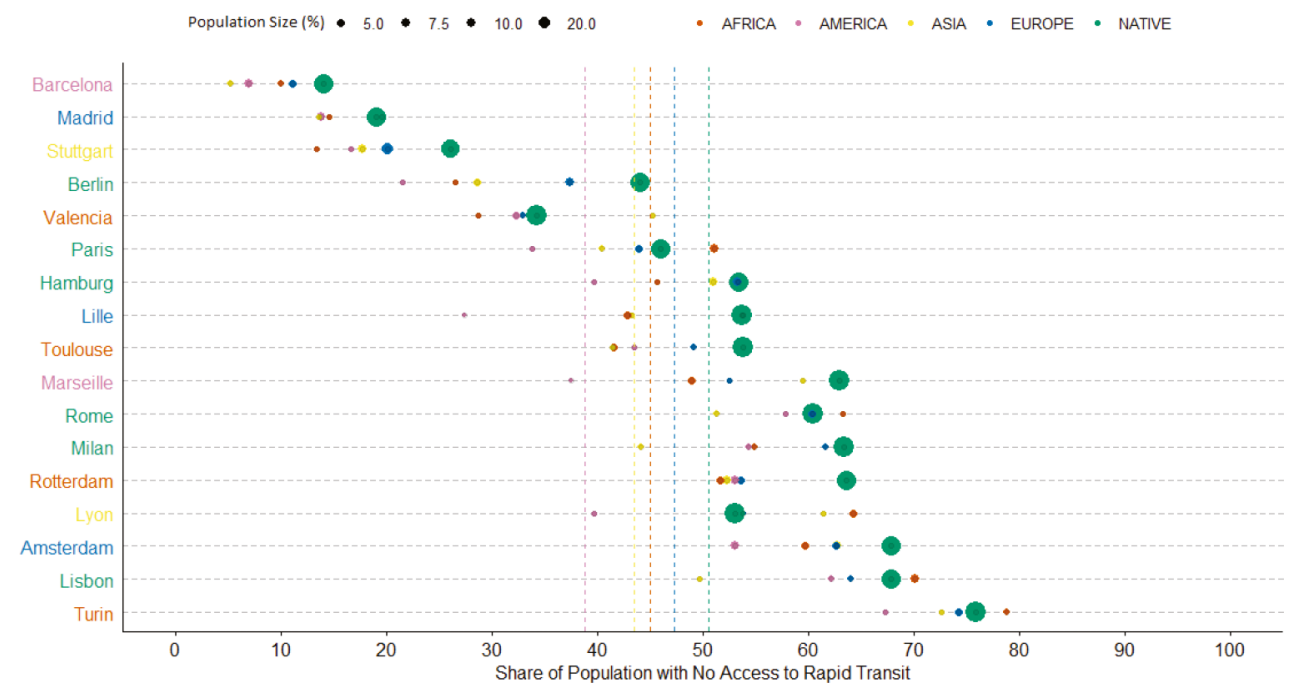

Figure 3: The share of population with no easy access to rapid transit. Vertical dashed lines represent the grand mean of the percentages of all cities per population group.

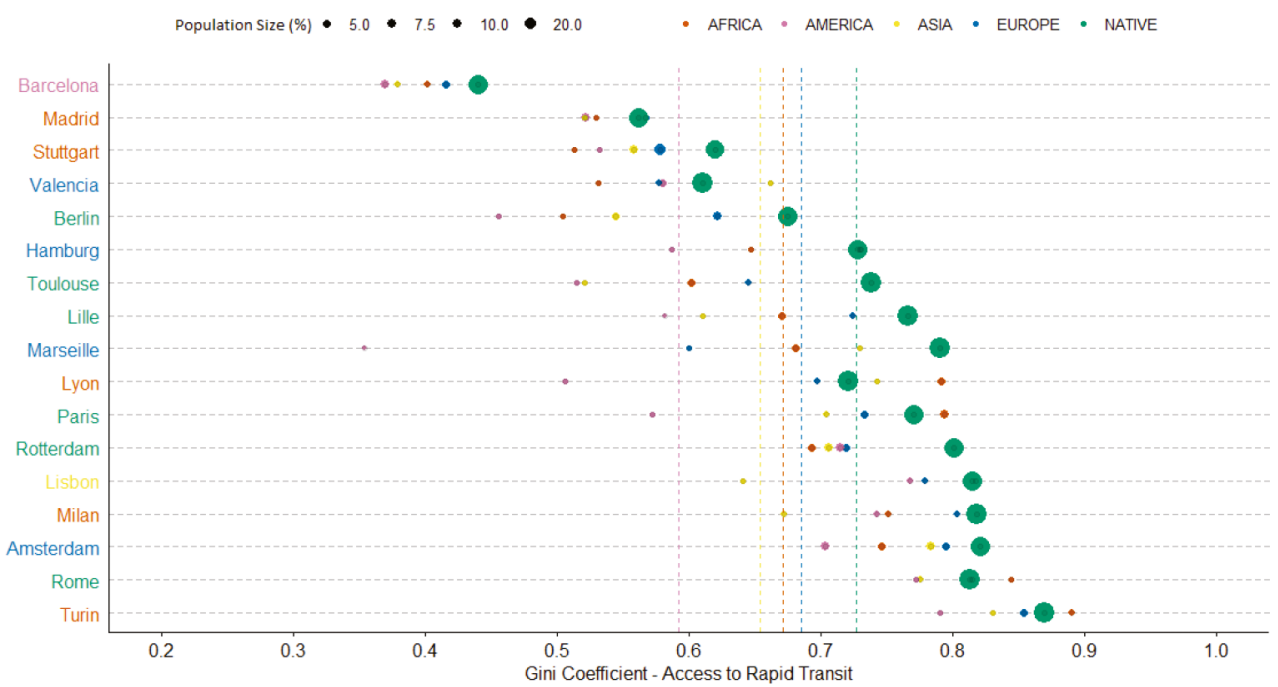

Figure 4: Gini coefficient analysis of rapid transit accessibility. Vertical dashed lines represent the grand mean of the Gini indicators of all cities per population group.

also evident in Europeans and the native-born population, which presented extremely high values in comparison to the other groups in many cities. Notably, in Turin, Rome, Milan, Amsterdam and Lisbon, the Gini values were higher than 0.78 . 


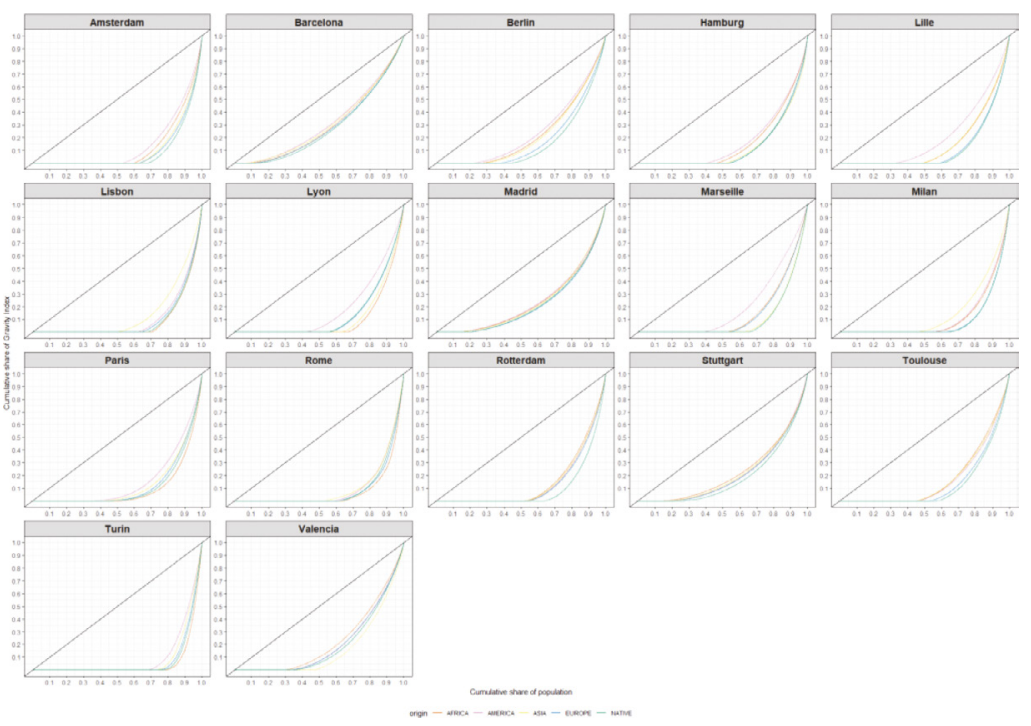

Figure 5: Lorenz curves of migrant and non-migrant groups and rapid transit accessibility.

\section{SUMMARY AND CONCLUSION}

This study is the first one that applied rapid transit accessibility and equity analysis in a big spatial dataset of migrants' concentrations in Europe. We developed a comparable gravitybased accessibility indicator to analyse and benchmark the level of access in subways and rail stations both between and within different migrant groups and cities. What is more, we performed Gini coefficient analysis, and we created Lorenz curves to explore the rapid transit inequality within various foreign-born and native-born populations. These measures were chosen for their relative simplicity and ease of understanding by a wide variety of practitioners and decision-makers in transportation, urban planning and social policy domains. So far, other authors of transit accessibility and equity studies applied their approach only in one city case [22] or a restricted number of territories [25] and not in a wider geographical region. Therefore, it was unclear how accessible and 'fair' the rapid transit systems are compared to other places and multiple ethnic population groups.

Overall, from our analysis, we found that in European cities it is notably difficult for people, regardless of their nationality, to live near frequent rapid transit stops.

Accordingly, we found that in 8 of 17 cities, almost all population groups and approximately more than half of them live outside the service areas of subways or suburban rails (Fig. 3). This result has substantial implications for urban and transportation policy and underlines the failures of the last decade's city and mobility planning in Europe. Similar findings have also been reached by other studies [34], [5]; however, further research is required to clarify explicitly the socioeconomic factors that influence and cause these difficulties for people to live closer to rapid transit.

Barcelona and Paris demonstrated substantial levels of accessibility in almost all groups, while, on the contrary, Lisbon, Amsterdam, Rotterdam and Rome were found to offer the worst rapid transit accessibility of all cities. Our analysis indicated that American migrants 
on average had better scores in the accessibility index than any other population group, while, on the contrary, African migrants had the worst performance. In some cities, the chasm between the groups was striking. For example, in all French cities, Americans had considerable higher accessibility in contrast to all other groups. Future expansions of the subway lines and improvements in service frequencies might close this gap, especially in Paris, where the Grand Paris Express project is expected to deliver 68 new stations and $200 \mathrm{~km}$ of additional railway lines. Another interesting finding was the pattern of the native-born population in the Dutch and the German cities. We found that in these urban areas, non-migrants always had worse accessibility results than the foreign-born population. A possible explanation of this result might be the high modal share of cycling in the native-born population and the increased use of public transport from migrants. Besides, recent European empirical studies [29], [1] showed that migrants do not cycle and drive as much as non-migrants do, which in turn does not allow them to live great distances from the transportation hubs.

Equity assessment revealed a landscape of high inequality in rapid transit supply across Europe. In almost all cities and groups, except Barcelona, the Gini coefficient values were higher than 0.5. In particular, in Italian, Dutch and Portuguese cities, the levels of inequality across all migrant and non-migrant groups were significantly high, and further investigation of the urban mobility system in these cities is required to ensure that inclusive transportation solutions are put into practice. Moreover, the native-born population, which shows a more dispersed residential pattern in all cities, had the highest transit inequality level, while Americans had the lowest. Importantly, the ultimate level of inequality was highlighted for Africans in Turin, where $88 \%$ of the population shared only $10 \%$ of the transit. In this case, strong housing affordability mechanisms and planning controls around subways are needed in order to minimise the rapid transport-related social exclusion. Other transit equity studies from Australia indicated that $70 \%$ of the population in Melbourne and Perth receives only $19 \%$ and $33 \%$ of transit supply, respectively [22], [25]. However, it is difficult to compare these results from Australia with those in Europe, mainly due to methodological differences in measuring and defining transit access, but we can conclude that cities in general around the world hardly satisfy the demand for public transportation in an equal way.

This article has only delved into the ethnic background of population demographics to measure rapid transit accessibility and equity in European cities. It would be stimulating to add into our analysis several other demographics of migrants and non-migrants, such as age, gender, income, car occupancy or employment, as well as additional transportation services in the city, such as bus and tram lines, or bike-sharing stations, in order to shed more light about transportation accessibility and equity in the city. In the future, we would like to get a better understanding of the transportation-related social exclusion processes in cities, since we could track and compare, in a spatiotemporal manner, both accessibility and equity indicators.

\section{ACKNOWLEDGEMENTS}

We thank the European Commission's JRC for the D4I initiative and the creation of the D4i spatial dataset. Additionally, we thank the National Statistical Institutes: ISTAT (Italy), INE (Spain), INE (Portugal), DESTATIS (Germany), INSEE (France) and CBS (Netherlands) for providing the original data from the 2011 Census. 


\section{REFERENCES}

[1] Welsch, J., Conrad, K. \& Wittowsky, D., Exploring immigrants travel behaviour: empirical findings from Offenbach am Main, Germany. Transportation, 45, pp. 733-750, 2018.

[2] OECD, Working Together for Local Integration of Migrants and Refugees, OECD Publishing, Paris, 2018. [Online]. Available: https://doi.org/10.1787/9789264085350-en.

[3] Blumenberg, E. \& Evans, A. E., Planning for demographic diversity: the case of immigrants and public transit. Journal of Public Transportation, 13(2), pp. 23-45, 2010.

[4] Blumenberg, E., Moving in and moving around: Immigrants, travel behavior, and implications for transport policy. Transportation Letters, 1(2), pp. 169-180, 2009.

[5] Marks, M., Mason, J. \& Oliveira, G., People Near Transit: Improving Accessibility and Rapid Transit Coverage in Large Cities, Insitute for Transportation \& Development Policy, 2016. [Online]. Available: https://www.itdp.org/wp-content/uploads/2016/10/ People-Near-Transit.pdf.

[6] Zhao, F., Chow, L. F., Li, M. T., Ubaka, I. \& Gan, A., Forecasting transit walk accessibility: regression model alternative to buffer method. Transportation Research Record, 1835, pp. 34-41, 2003.

[7] Saif, M. A., Zefreh, M. M. \& Torok, A., Public transport accessibility: A literature review. Periodica Polytechnica Transportation Engineering, 47(1), pp. 36-43, 2019.

[8] Adli, S. N., Chowdhury, S. \& Shiftan, Y., Justice in public transport systems: A comparative study of Auckland, Brisbane, Perth and Vancouver. Cities, 90, pp. 88-99, 2019.

[9] El-Geneidy, A., Buliung, R., Diab, E., van Lierop, D., Langlois, M. \& Legrain, A., Non-stop equity: Assessing daily intersections between transit accessibility and social disparity across the Greater Toronto and Hamilton Area (GTHA). Environment and Planning B: Planning and Design, 43(3), pp. 540-560, 2015.

[10] Currie, G., Quantifying spatial gaps in public transport supply based on social needs. Journal of Transport Geography, 18(1), pp. 31-41, 2010.

[11] Batty, M., Accessibility: in search of a unified theory. Environment and Planning B: Planning and Design, 36, pp. 191-194, 2009.

[12] Hansen, W., How Accessibility Shapes Land Use. Journal of the American Planning, 25(2), pp. 73-76, 1959.

[13] Geurs, K. \& van Wee, B., Accessibility evaluation of land-use and transport strategies: review and research directions. Journal of Transport Geography, 12(2), pp. 127-140, 2004.

[14] Mavoa, S., Witten, K., McCreanor, T. \& O'Sullivan, D., GIS based destination accessibility via public transit and walking in Auckland, New Zealand. Journal of Transport Geography, 20, pp. 15-22, 2012.

[15] Poelman, H. \& Dijkstra, L., Measuring access to public transport in European cities, European Commission, DG REGIO Working Papers. [Online]. Available: https:// ec.europa.eu/regional_policy/sources/docgener/work/2015_01_publ_transp.pdf.

[16] Nassir, N., Hickman, M., Malekzadeh, A. \& Irannezhad, E., A utility-based travel impedance measure for public transit network accessibility. Transportation Research Part A: Policy and Practice, 88, pp. 26-39, 2016.

[17] Geertman, S. C., van Eck, R. \& Jan, R., GIS and models of accessibility potential: an application in planning. International Journal of Geographical Information Systems, 9(1), pp. 67-80, 1995. 
[18] Piovani, D., Arcaute, E., Uchoa, G., Wilson, A. \& Batty, M., Measuring accessibility using gravity and radiation models. R. Soc. Open Sci, 5(171668), 2018.

[19] Geurs, K. \& van Eck, R., Accessibility Measures: Review and Applications - Evaluation of accessibility impacts of land-use transport scenarios, and related social and economic impacts, RIVM, report 408505 006, National Institute of Public Health and the Environment. 2001. [Online]. Available: http://www.rivm.nl/bibliotheek/rapporten/408505006.pdf.

[20] Coppola, P., Papa, E. \& Angiello, G., Gravity-Based Accessibility Measures (GRA$\mathrm{baM}$ ) for sustainable development of Rome urban area. in COST Action TU1002 - Assessing usability of accessibility instruments, Brussels, 2014, pp. 65-72.

[21] Hasnine, S. M., Graovac, A., Camargo, F. \& Habib, K. N., A random utility maximization (RUM) based measure of accessibility to transit: Accurate capturing of the firstmile issue in urban transit. Journal of Transport Geography, 74, pp. 313-320, 2019.

[22] Delbosc, A. \& Currie, G., Using Lorenz curves to assess public transport equity. Journal of Transport Geography, 19, pp. 1252-1259, 2011.

[23] Lucas, K., van Wee, B. \& Maat, K., A method to evaluate equitable accessibility: combining ethical theories and accessibility-based approaches. Transportation, 43, pp. 473-490, 2016.

[24] Ramjerdi, F., Equity measures and their performance in transportation," Transportation Research Record, 1983(1), pp. 67-74, 2006.

[25] Ricciardi, A. M., Xia, J. \& Currie, G., Exploring public transport equity between separate disadvantaged cohorts: a case study in Perth, Australia. Journal of Transport Geography, 43, pp. 111-122, 2015.

[26] Kaplan, S., Popoks, D., Prato, C. G. \& Ceder, A., Using connectivity for measuring equity in transit provision. Journal of Transport Geography, 37, pp. 82-92, 2014.

[27] Ding, J., Zhang, Y. \& Li, L., Accessibility Measure of Bus Transit Networks. IET Intelligent Transport Systems, 12(7), pp. 682-688, 2018.

[28] Welch, T. F. \& Mishra, S., A measure of equity for public transit connectivity. Journal of Transport Geography, 33, pp. 29-41, 2013.

[29] Haustein, S., Kroesen, M. \& Mulalic, I., Cycling culture and socialization: modeling the effect of immigrant origin on cycling in Denmark and the Netherlands. Transportation, p. Article in Press, 2019.

[30] Flavia, T. \& Rohr, C., The impact of migration on transport and congestion, RAND Corporation. 2011. [Online]. Available: https://www.rand.org/pubs/technical_reports/ TR1187.html.

[31] EUROSTAT, High-Density Clusters. 2017. [Online]. Available: https://ec.europa.eu/eurostat/web/gisco/geodata/reference-data/population-distribution-demography/clusters.

[32] Tintori, G., Alessandrini, A. \& F. Natale, Diversity, residential segregation, concentration of migrants: a comparison across EU cities, JRC Technical Reports, European Commission. 2018. [Online]. Available: doi:10.2760/823648.

[33] Sevtsuk, A. \& Mekonnen, M., Urban network analysis: A new toolbox for measuring city form in ArcGIS. in Symposium on Simulation for Architecture and Urban Design, Orlando, FL, 2012.

[34] Rokem, J. \& Vaughan, L., Geographies of ethnic segregation in Stockholm: The role of mobility and co-presence in shaping the 'diverse' city. Urban Studies, p. Article in Press, 2018. 